\title{
The Use of Olfactory Stimulants to Improve Indoor Air Quality
}

\author{
Diotima von Kempski \\ DVK air vitalizing system Bäckergasse 240213 Düsseldorf, Germany \\ E-mail: Dvkempski@t-online.de
}

(received on December 11, 2001, accepted on April 12, 2002)

\begin{abstract}
The impact of indoor air quality on the well-being and comfort of a building's occupants are key to creating an indoor environment which increases human performance.

To date, efforts to improve indoor air quality have focused on creating thermal comfort and on developing technical means of reducing odor pollution. However, it has not yet been possible to translate these efforts into a corresponding improvement in the "dissatisfaction level" expressed by building occupants.

Conventional approaches are bound to remain incomplete because they fail to take account of physiological and psychological effects of the sense of smell. Acceptable indoor air quality can only be achieved if the reduction in air pollution is combined with the addition of natural olfactory stimulants with sufficient positive attributes. Indoor air will only be perceived as acceptable if olfactory criteria are taken into consideration in addition to the traditional criteria of thermal comfort.

Furthermore, it is necessary to set high standards for the use of the olfactory stimulants which are added to the indoor air. There are a number of specific requirements for the selection and dispersion of these substances.
\end{abstract}

Key words: olfaction, indoor, air quality, perception, well-being

\section{Introduction}

It is difficult to overstate the importance of indoor air quality. Research in the field of air conditioning has shown that indoor air quality has a significant influence on the comfort and well-being of occupants. In particular, air quality plays an important role in determining employee productivity. It is estimated that the annual benefit of upgrading all commercial buildings in the United States to ASHRAE-standards 621989 and 55-1992 [1] would amount to over \$ 50 billion or approximately $\$ 12$ per square meter per year (Dorgan 1994) [2].

Good indoor air quality is determined by two major attributes:

- The air should not carry any health risks.

- The air should be perceived as pleasant and fresh.

The first of these attributes is assessed by objective measures of air quality. Indoor air is generally regarded as acceptable, when it does not contain any known contaminants in harmful concentration (ASHRAE 1989) [3]. This includes measures of concentration of chemical agents, microorganisms, volatile organic compounds and carbon dioxide. Permissible limits are established for the respective con- centrations of pollutants. However with as many as 900 different hazardous substances present in any given building this assessment of indoor air is itself a complex and difficult process.

Adding another level of complexity to the measurement issues, the second attribute of good air quality is defined by subjective criteria. For a long time the attention has been focused on the contaminants concentrations in indoor air. Only more recently have the subjective criteria been added. This is important because a true picture of the effect of air quality on occupants requires the inclusion of the physiological and psychological factors measured by these subjective criteria.

The subjective criteria include two elements-thermal comfort (which depends on room temperature and humidity) and the perceived air quality (which depends on the odorous substances present in the air).

While thermal comfort has long been the goal of air conditioning systems, the influence of the sense of smell has only recently been researched.

Cain et al. (1983) [4] and Fanger et al. (1983) [5] have demonstrated that odor pollution directly influences the "dissatisfaction rate" of occupants. The re- 
search by Fanger (1988) [6] shows the percentage dissatisfied to be a function of the rate of ventilation air and the number of people occupying the space. On this basis a scale for evaluating air quality has been introduced. According to the scale the perceived air quality can be expressed in decipols, where 1 decipol is defined as the odor pollution caused by one average person (one olf) ventilated by $10 \mathrm{l} / \mathrm{sec}$. of unpolluted air.

The evaluation of decipol figures has, however, been called into question. In a European Union (EU) audit (European Audit Project to Optimize Indoor Air Quality and Energy Consumption in Office Buildings), there are indications that the dissatisfaction level may not rise significantly until a decipolvalue of 10 has been reached and that this depends on whether a trained or untrained test group is carrying out the air quality evaluation (Bluyssen et al. 1995) [7] Bischof et al.1999 [8]. The basic problem of air pollution and its effects on indoor air quality has, however, been confirmed by the investigations. Independent of the evaluation of the decipol levels, the results of the EU Audit show that the percentage dissatisfied remains between $15 \%$ and $40 \%$ even when the outdoor air is adjusted to an optimum level and when the best available filtration is used (Finke 1995) [8]. Complaints of stuffy and artificial air persist.

The reason why the percentage dissatisfied is still relatively high is not so much because of inadequate technical equipment available but because current approaches fail to take into account that our perception or behavior is not only influenced negatively by odor pollution, but also by the absence of positive stimulating substances (Brockmeier and von Kempski 1992) [9].

An approach whose primary concern has been to reduce or remove negative olfactory substances in the air is valid but remains incomplete since it ignores the neurophysiological and psychological research findings from the field of aromachology.

\section{Olfactory Comfort}

An assortment of odor molecules is found in untreated air. With every breath they reach the upper nasal passages called the cleft, which contain the olfactory epithelium. The average epithelium contains roughly 30 millions receptor cells, each of which has microscopic hairs (cilia). Odor substances bind chemically with the cilia, beginning a process, which results in electrical messages being passed to the brain along the olfactory nerves. Within the brain, the olfactory bulb receives sensory inputs and communicates these with a number of other regions including the limbic system, the hypothalamus, and the cortex. The limbic system is probably the most complex, one of the most important, and one of the least well understood parts of the brain. It controls mood and emotions, our perception of the environment as well as the formation, storage, and retrieval of memories. Stimuli which are transmitted, to the limbic system cannot consciously be blocked. All olfactory stimuli therefore influence our emotions (von Kempski 1996) [10]. They also contribute to a wealth of retained memories - the olfactory sense is stored in the brain for a longer period of time than any of the other senses.

To date, olfactory research has identified over 6,000 different olfactory substances of which up to 400 are generally found in indoor air.

A number of surveys on the neuro-physiological and aromachological influence of odors indicate that the sensory assessment of olfactory substances requires analysis of the following four criteria:

- Detectability

- Intensity

- Quality or character

- Hedonic note.

Of these four criteria (which are all detailed in the ASHRAE-handbook) [11] the hedonic note is of special importance. It decides whether the olfactory substance is perceived as pleasant or unpleasant. Depending on the quality, the intensity, and the detectability of the olfactory substance, the hedonic note determines whether it influences people positively or negatively. Research over the past few years has demonstrated how olfactory substances of required quality and hedonic note are capable of increasing individuals' well-being.

- Lorig and Schwartz (1988 [12] and 1990 [13]) studied the neurological and physiological effects of different olfactory substances and found that electro-physiological activity, especially in the parts of the brain which are important for alertness and concentration, can be influenced positively or negatively depending on the olfactory substances used.

- Kobal (1992) [14] measured electrical brain activity to determine that cognitive processes can be influenced in a controlled manner by the administration of various odors to the right or left nostril.

- Kikuchi (1991) [15] explored the effect of 5 odorous substances on the central nervous system. Certain pleasant odors were found to increase both heart rate and contingent negative variation (CNV). Moreover, the heart rate and $\mathrm{CNV}$ tended to vary coincidentally under the same odor conditions.

- Sogano (1984) [16], Yoshida et al. (1989) [17] and Ishitoya (1991) [18] independently identified a number of olfactory substances which differentially influence the alpha and the delta waves which are 
indicators of mood.

- Harnisch (1982) [19] proved in a number of experiments (using the heart rate as a measure of fear) that pleasant odors are able to reduce fear.

- More recently, Alaoui-Ismaili et al. (1997) [20] analyzed the neuro-physiological effects of olfactory substances with negative and positive hedonic notes. They demonstrate how substances with different hedonic notes not only positively and negatively influence moods but also how these subjective perceptions themselves correspond to neurophysiological symptoms. For example, specific positive olfactory substances can decrease physiological stress resulting in normalization of neurophysiological symptoms such as skin resistance, skin temperature, breath frequency and heartbeat.

The above findings have been confirmed by additional research in the field of aromachology.

- As early as 1987, Warren (1987) [21] reported that specific odors found in nutmeg oil, maze extract, neroli oil, valerian oil, myristicin, isoelemicin, and elemicin, can reduce stress in humans as well as reduce stress-related blood pressure.

- The research conducted by Dember et al. (1992) [22] is of special significance. They measured the effect of using olfactory substances to enhance the concentration of night shift workers. They found that the effect was particularly strong for subjects who had previously exhibited difficulties concentrating.

This selection of research leads us to the conclusion that it is not acceptable to classify olfactory substances in indoor air as inherently negative. It is important to include the criteria of hedonic note, as defined in the ASHRAE-Handbook (1989) [23].

In the same way that a sound proofed space is not an ideal environment and would likely lead to health problems, complete elimination of olfactory substances will not lead to a significant decrease in the dissatisfaction rate of building occupants. Individuals breathe odor molecules which influence their mood as well as their physiological and psychological state. Exposure to "purified" air will deprive individuals of the stimuli they require, inevitably leading to discomfort. To ensure well-being, individuals require olfactory substances - especially those found in natural air (von Kempski and Goepfert 1997) [24].

Olfactory comfort is therefore not only defined by the absence of negative olfactory substances but also as a condition of mind that expresses satisfaction with the olfactory environment created by positive stimulating olfactory substances in the indoor air.

Buildings situated in metropolitan areas typically lack these positive olfactory substances. The substances are generally not found in sufficient quanti- ties in the outside air and filters and cleaning mechanisms within HVAC-systems remove them along with any negative substances. Positive olfactory substances therefore have to be added to the ventilation system.

\section{Requirements for the Use of Olfactory Substances}

In the past a number of errors have been made in the implementation of olfactory systems, potentially leading to increases in olfactory discomfort. (von Kempski 1999) [25].

A number of systems and techniques whose only goal is to increase sales are still in use. They employ fragrant substances that are clearly perceived and that are deployed for marketing purposes. This frequently leads to "odor annoyance"- a step backwards in the effort to improve the quality of indoor air. In order to be effective, the use of olfactory substances to improve air quality has to meet specific aromachological and technical requirements.

\section{Aromachological Requirements for Olfactory Substances}

The correct selection and design of olfactory substances is critical. The correct substances are very different from what is generally known as perfume. Perfume is an aesthetic material that is also frequently used for scented products. In order to improve indoor air quality olfactory substances should be employed which replicate the constituents of natural outdoor air. These substances are deployed at concentrations at which are below individuals' perception threshold. They are complex olfactory substances which are selected to match the specific activities and expectations of building occupants.

The following four factors have to be analyzed in order to select the correct olfactory substances:

- Average number of room occupants

- Odor emissions, for example from construction materials, carpeting, and cleaning chemicals

- Activity taking place in the building

- Expectation of occupants with respect to indoor air given the activities taking place in the space

The first two factors determine the impact of olfactory pollutants on the well being of occupants. The last two factors serve to ensure that only those olfactory additives are employed that are tailored to the expectations of a building's occupants.

Aromachological research provides the blueprint for the use of tailored substances which are assembled based on the above analyses. Substances are selected based on their specific mood and activity that they stimulate.

An individual's response to an odor stimulus may be categorized by a combination of eight mood states 
which are represented schematically in Fig. 1. If one visualizes a vertical " $y$ "-axes down the center of the figure, the four mood states to the right are positive states which one should seek to enhance while the four negative states on the left need to be diminished. If one further visualizes a horizontal " $x$-"axes, the upper half of the circle shows the "active" moods and the bottom half the "passive" ones. Mono-odors however are unable to create the desired "natural" effects. The effect of mono-substances is multifaceted. For example, some substances can exhibit both relaxing and stimulating effects while another relaxes but is also a depressant. What this means is that more complex olfactory compositions are required to target specific characteristics (Ramsbotham 1988) [26].

In addition, it is important to recognize that not all substances are suitable for dispersion in indoor air. There are a number of different characteristics of these substances that have to be taken into account including their perceived intensity, their volatility, their stability with respect to pressure and temperature, the nature of the carrier materials, and any changes in these values at different levels of humidity. The substances have to withstand the conditions within the air conditioning vents as well as exhibit the required characteristics once dispersed in the indoor air. [28]

\section{Technical Requirements}

Until recently, the necessary systems have not been available to distribute the olfactory substances in the indoor air with sufficient accuracy of dosage. Irregular distribution of the fragrances cannot be tolerated as this will cause olfactory discomfort.

Two requirements are key to the selection of the appropriate olfactory system.

- The olfactory substances have to be distributed within the indoor air in a constant and uniform manner.

- The concentration of the olfactory substances has to be maintained at a level between the detection threshold and the recognition threshold

Uneven distribution will lead to overdose of the substances with the result that the dissatisfaction rate of occupants will increase significantly. Research by Cain et al. (1988) [27]. and studies by Teerling (1992) [28]. and Fanger et al. (1991) [29] have already demonstrated the importance of maintaining the correct concentration levels.

Teerling (1992) [28] studied the effect of indoor air treated with olfactory stimulants on purchasing behavior in shops and reported that the well-being of customers could be increased significantly only when the olfactory substances were not perceptible.

Fanger et al. (1991) [30] carried out preliminary tests with an air vaporizing system and came to the conclusion that the decipol values can be reduced significantly by adding positive olfactory stimulants to the indoor air. Decipol Fig. rise again significantly, however, as soon as a certain concentration of the olfactory stimulants in the indoor air is exceeded. The excessive concentration produces a negative reaction from a subset of the occupants as they reject the inherently positive odor as unpleasant.

However, both surveys used olfactory substances which were not maintained at constant levels of concentration and, importantly, which were not distributed through air conditioning systems. No control system was available to regulate the dosage with respect to indoor air parameters such as humidity and temperature.

In 1995 and 1996 in-house studies were completed with more accurate air distribution systems. In these studies it was possible to control the olfactory substances in the indoor air with a high level of precision.

An evaporation system was installed as an add-on component to the by-pass of an existing air conditioning system in a retail space. A purpose-built control system guaranteed that the concentration of olfactory substances in the indoor air was uniform. Sensors in the duct as well as in the retail space provided measurements of four technical room air parameters which allowed the dosage to be adjusted. These four parameters determine the perception of olfactory substances.

- Air volume

- Ratio of outdoor/circulated air

- Temperature

- Humidity

The readings of the sensors are passed to a control device which incorporates a DDC management system.

An olfactory substance with a positive hedonic note and a density of $0.945 \mathrm{~g} \cdot \mathrm{ml}^{-1}$ was distributed into the retail space through the air conditioning system at 3 different intensities. The temperature was maintained at $19^{\circ} \mathrm{C}$, the pressure at $850 \mathrm{~mm}$ Mercury

\section{Mood Categories}

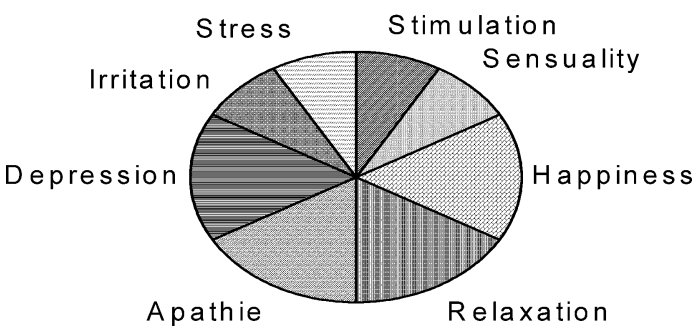

Fig. 1 


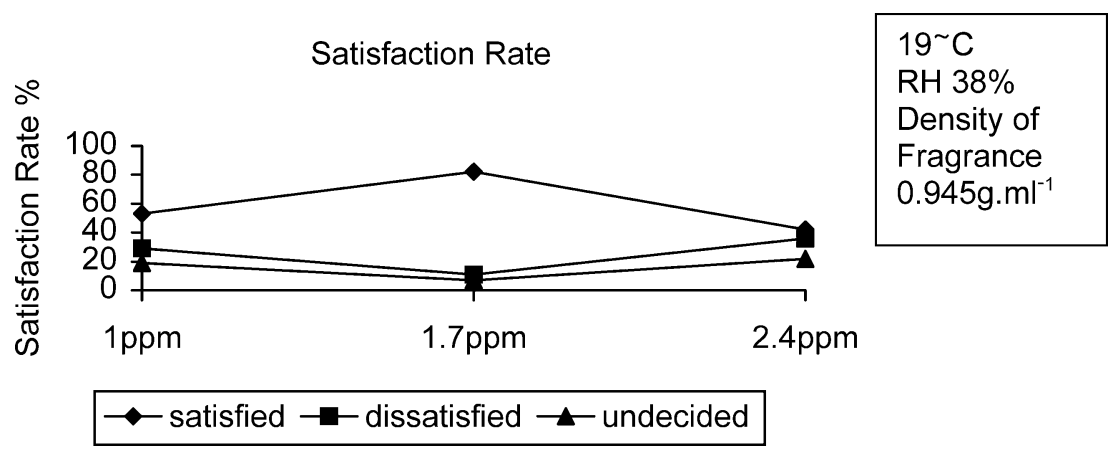

Fig. 2

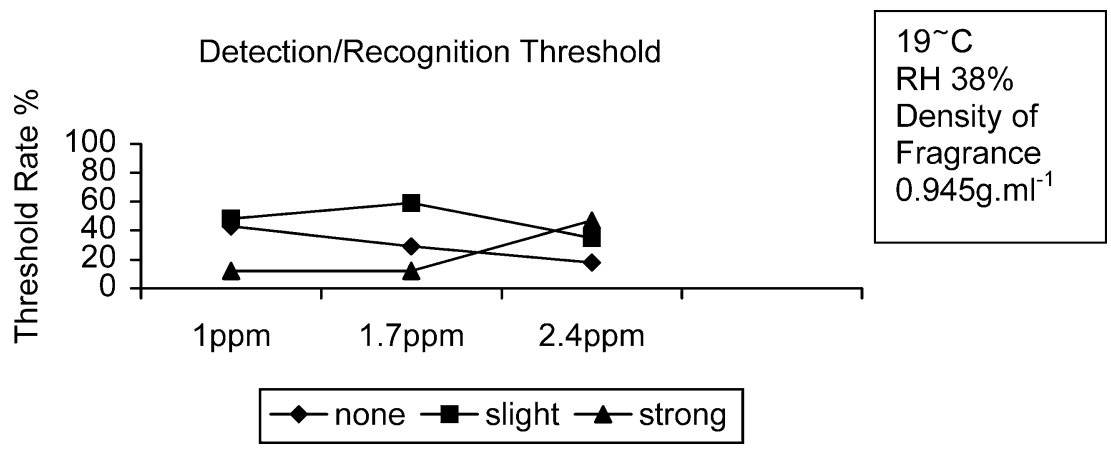

Fig. 3

with a relative humidity of $38 \%$. For intervals each of 1 hour, the concentration within the indoor air was $1 \mathrm{ppm}, 1.7 \mathrm{ppm}$ and $2.4 \mathrm{ppm}$. Two and half hours were allowed between test intervals in order to "clear" the air and to attain the desired concentrations. The HVAC system was running with an air change rate of 3 per hour.

40 untrained individuals between 25 and 70 years of age were asked whether they perceived the indoor air to be "pleasant", "neutral" or "unpleasant". Additionally, they were asked whether they noticed the odor "strongly", noticed the odor "slightly", or noticed nothing at all. The research took place over the course of 3 weeks ( 5 days a week) with a daily exposure over 7-8 hours. On Tuesdays, Wednesdays and Fridays they were asked a series of questions first thing in the morning. On Mondays and Thursdays the individuals were asked questions when they arrived at the office in the morning and then again at $3 \mathrm{pm}$. The late afternoon questioning was intended to test individuals' perception after they had been given the opportunity to acclimate to the indoor environment.

The results (see Fig. 2) show that, at the lowest level of concentration, most individuals perceived the air to be neutral but the dissatisfaction rate (the percentage of individuals describing the air as unpleasant) of less than $30 \%$ was already quite high. At a concentration of $1.7 \mathrm{ppm}$ the dissatisfaction rate decreased to $11 \%$. The percentage perceiving the air to be pleasant showed a corresponding increase from $53 \%$ to $82 \%$. At the highest level of concentration however the improvements are reversed-the dissatisfaction rate increased to $36 \%$.

The questions relating to whether the test subjects noticed the odor indicated that the detection threshold of the substance used was roughly $1 \mathrm{ppm}$. The results from the test subjects also indicated that the optimal satisfaction level lies between the detection and the recognition threshold. The estimate of the detection threshold was in line with findings from earlier research conducted with the same substance.

Fig. 3 shows that at a concentration level of 2.4 ppm most of the test subjects noticed the odor as "strong". However, those individuals who did not immediately "notice" an odor, even at a concentration of $2.4 \mathrm{ppm}$, generally did not change their mind. Obviously, personal factors play an important role and can only be dealt with by questioning the background of the subjects with respect to health, eating, drinking smoking habits, etc.

The same survey was repeated half a year later under the similar conditions except that the temperature was changed to $21^{\circ} \mathrm{C}$ and relative humidity to $46 \%$. Our ability to make comparisons between the two tests is somewhat limited by the fact that the test groups also changed.

However, Fig. 4 and Fig. 5 demonstrate that there are a number of remarkable differences relative to the 
Satisfaction Rate

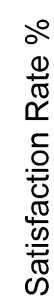

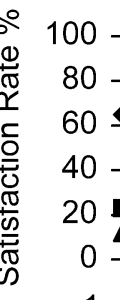

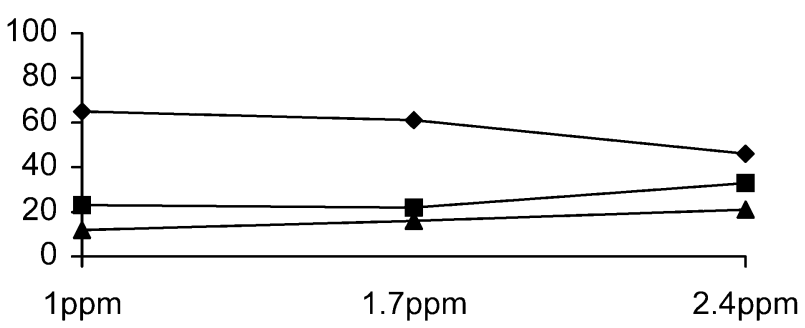

$\bullet$ satisfied $\neg$-dissatisfied $\neg \leftarrow$ undecided

Fig. 4

\section{Detection/Recognition Threshold}

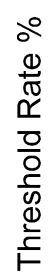

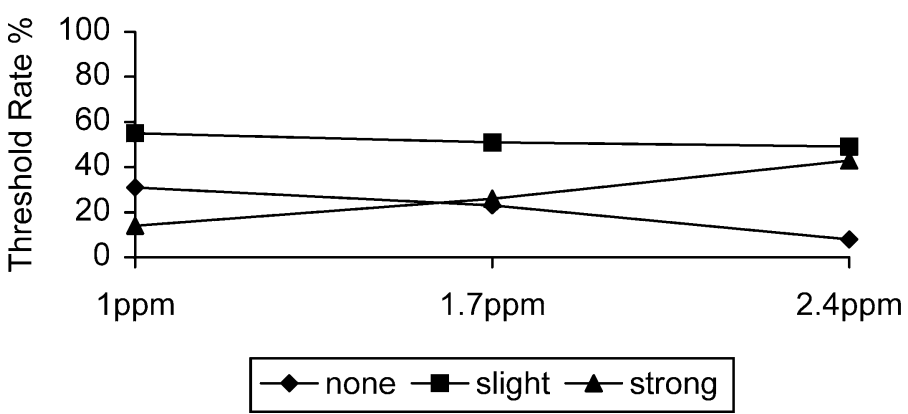

$21^{\sim} \mathrm{C}$

$\mathrm{RH} 46 \%$

Density of

Fragrance

$0.945 \mathrm{~g} \cdot \mathrm{ml}^{-1}$

Fig. 5

first set of findings. The concentration level at which dissatisfaction levels were minimized had decreased. Dissatisfaction levels were lowest at $1 \mathrm{ppm}$ and increased at both the $1.7 \mathrm{ppm}$ and $2.4 \mathrm{ppm}$ levels.

Fig. 5 shows that at the low level of concentration a greater proportion of test subjects "noticed" the odor. It follows that the increase in temperature and relative humidity shifted the perceived intensity for a given level of concentration of the olfactory substances. This resulted in a downward shift of the detection and recognition thresholds.

\section{Discussion}

The research described above indicates the importance of thermal parameters such as humidity and temperature on olfaction. Furthermore it demonstrates the need for a control system to maintain a uniform concentration of the olfactory substances between the detection and recognition thresholds. Regular measurements of the fluctuating parameters (e.g., duct and room humidity, duct and room temperature, variable air volume, the ratio of outdoor to circulating air) are required to make the corresponding adjustments to the dosage levels.

Fig. 6 depicts an example of an olfactory system incorporated in an air conditioning system. Elec-

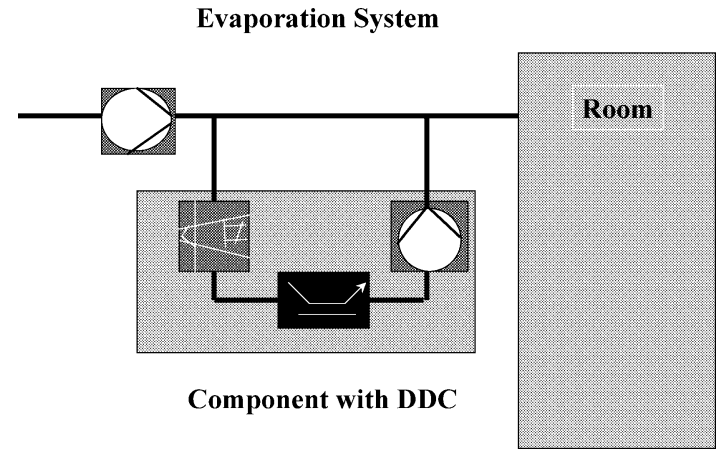

Fig. 6

tronic measurements are transmitted by the central DDC-unit to the local DDC-unit of the olfactory system which then calculates the required changes.

Accurate dosages of olfactory substances can be attained by using an evaporation system as long as the evaporation surface is of sufficient size. Control over concentration levels is maintained by controlling molecular emission of the olfactory substances in the partial airstream.

\section{Conclusion}

Research clearly shows that the addition of olfactory substances to the indoor air can significantly in- 
crease the satisfaction rate of building occupants.

It is necessary to create both olfactory and thermal comfort to achieve a significant improvement in IAQ. Olfactory comfort can only be achieved if, in addition to eliminating negative substances, positive substances are added to the indoor air.

The use of such positive substances requires a uniform distribution into the indoor air at just above the detection threshold. If the dosage is too low the effect may not be complete, but too high a dosage or an unevenly distributed dosage turns olfactory comfort into discomfort. To prevent this from occurring it is important to use only those systems which are capable of maintaining an equal concentration of odor in the indoor air.

In order to maintain the correct dosage, thermal factors also have to be taken into account. With an increase in temperature and humidity the perception of odor is much stronger, with the result that the acceptance level of occupants may decrease if dosages are not adjusted.

In order to realize a concept of adding natural olfactory stimulants to indoor air successfully three requirements have to be fulfilled.

- The HVAC-system itself must be in a good state.

- Only complex olfactory structures should be used; on no account should mono-odors be adapted. The olfactory substances must be matched to the rooms activities and the respective expectations of the occupants.

- Olfactory stimulants should only be added via ventilation or air conditioning air streams in order to secure a complete mixture of ventilated air and odor. Furthermore only systems which ensure that the dosage is kept just above the detection threshold and which avoid excessive odor concentrations should be used.

Research results show a significant reduction in decipol values under certain conditions. However, it is necessary that guidelines be produced for the use of olfactory stimulants to attain the high standard discussed above.

Further research should also be conducted on the influence of the optical and acoustical environment on perception of indoor air quality. Findings in the field of aromachology have shown that optical stimuli (especially colors) can influence the perception of smell or of temperature. For example, the color blue in combination with certain odors such as peppermint leads to a perception of lower temperature. Occupants feel colder than they would with neutral color surroundings and without the addition of the olfactory substances. [34]

The use of olfactory substances in HVAC systems is an important element in improving indoor air qual- ity and creating a "healthy" building. It is an economically attractive means of increasing the satisfaction rate of building's occupants.

\section{References}

1. ASHRAE. 1989. ANSI/ASHRAE Standard 62-1989, Ventilation for acceptable indoor air quality. Atlanta: American Society of Heating, Refrigerating, and AirConditioning Engineers, Inc.

2. Dorgan, C. E., Willman, A. J. and Dorgan, C. B. 1994. Productivity link to the indoor environment estimated relative to ASHRAE 62-1989, Healthy Buildings 1994, Budapest, Hungary.

3. ASHRAE. 1989. 1989 ASHRAE Handbook of fundamentals, chp. 12.

4. Cain, W. S., Leaderer, B. P., Isseroff, R., Berglund, L. G., Huey, J., Lipsitt, E. D., Perlman, D. 1983. Ventilation requirements in buildings 1: Control of occupancy odor and tobacco smoke odor, Atmospheric Environment, Vol. 17, pp. 1183-1197.

5. Fanger, P. O. and Berg-Munch, B. 1983. Ventilation and body odor, Proc. of An Engineering Foundation Conference on Managment ot Atmospheres in Tightly Enclosed Spaces, ASHRAE, Atlanta, pp. 45-50.

6. Fanger, P. O. 1988. Introduction to the olf and decipol units to quantify air pollution perceived by humans indoors and outdoors, Energy and Buildings, Vol. 12.

7. Bluyssen, P. M., E. de Oliveira Fernandes, L. Groes, G. H. Clausen, P. O. Fanger, O. Valbjorn, C. A. Bernhard, C. A. Roulet, 1995, European Audit study in 56 buildings: conclusion and recommodations, Healthy Buildings '95, Milano, vol. 3., pp 1335-1340

8. Bischof, W. et al. Proklima-History, Aim and Study Design Indoor Air 99, Edinburgh, Vol. 5, pp. 276381

9. Finke, U. 1995. Luftqualität in deutschen Bürogebäuden, ki Luft und Kältetechnik, Vol. 3, p. 125.

10. Brockmeyer, H., von Kempski, D. 1992. "Indoor AirQuality”-Neue Aspekte zur Luftverbesserung der empfundenen Luftqualität, ki Klima Kälte Heizung, Vol. 10, pp. 378-381.

11. von Kempski, D. 1996. Duftklimatisierung und Indoor Air Quality-Sehnsucht nach natürlicher Luft, CCI Clima Commerce International, Vol. 10, pp. 24 27.

12. ASHRAE. 1989. 1989 ASHRAE Handbook of fundamentals, chp. 12.

13. Lorig, T. S. and Schwartz, G. E. 1988. Brain and odor I: Alteration of human EEG by odor administration, Psychobiology, Vol. 16, pp. 281-289.

14. Lorig, T. S. and Roberts, M. 1990. Odor and cognitive alteration of the contingent negative variation, Chem Senses, Vol. 15, pp. 537-545.

15. Kobal, G. and Hummel, T. 1992. Olfactory evoked potential activity and hedonics, in Fragrance: The Psychology and Biology of Perfume, S. Van Toller and G. H. Dodd, eds, Londong: Elsevier, pp. 175194.

16. Kikuchi, A., Tanida, M., Uenoyama, S., Abe, T. and Yamaguchi, H. 1991. Effect of odours and cardiac re- 
sponse pattern in a reaction time task, Chem Senses, Vol. 16, p. 183.

17. Sogano, H. 1984. Effects of odours on mental function, Chem Senses, Vol. 14, p. 303.

18. Yoshida, T., Sorito, S., Iida, T., Yamamura, M. and Kanamura, S. 1989. Effect of odours on frequency fluctuation of brain waves. Chem Senses, Vol. 14, p. 311.

19. Ishitoya, T. 1991. Effects of a fragrance on stress and fluctuation of EEG, Fragrance Journal, Vol. 19(92), pp. 50-54 (in Japanese).

20. Hanisch, E. 1982. The calming effect of fragrances and associated remembrances, drom Report "The Nose, Part 2" pp. 18-19.

21. Alaoui-Ismaili, O., Vernet-Maury, E., Dittmar, A., Delhomme, G. and Chanel, J. 1997. Odor Hedonics: Connection with emotional response estimated by Autonomic Parameters, Chem Senses, Vol. 22, pp. 237-248.

22. Warren, C. B., Munteanu, M. A., Schwartz, G. E., Benaim, C., Walter, H. G., Leight, R. S., Withycombe, D. A., Mookherjee, B. D. and Trenkle, R. W. June 9, 1987. Method of causing the reduction of physiological and/or subjective reactivity to stress in humans being subjected to stress conditions, US patent number 4 , pp. 671, 959 .

23. Dember, W. N.,Warm, J. S., and Parasuraman, R. 1992. Effects of olfactory stimulation on performance and stress in a visual sustained attention task, J. Soc Cosm Chem, Vol. 42, pp. 199-210.

24. ASHRAE. 1989. 1989 ASHRAE Handbook of fundamentals, chp. 12 .

25. von Kempski, D. and Goepfert, A. 1997. Improving indoor air quality through the addition of olfactory stimulants, Clima 2000-Brüssel 1997, p. 4 ff.

26. von Kempski, Diotima, 1999 REZ Raumluft-Essenzen-Zugabe Ein kleiner Leitfaden über Grundlagen der Anwendungsmöglichkeiten, Fachwissen im Promotor Verlag, Karlsruhe.

27. Ramsbotham, J. 1988. The development of fragrances with positive psychological benefits, Cosmesi, Dermatologica 44, pp. 85-92.

28. Calkin, Robert R., Jellinek, J. Stephan 1994, Perfumery Practice and Principles, John Wiley \& Sons.

29. Cain, W. S., Stevens, J. C. and Burke, R. J. 1988. The variability of olfactory thresholds, Chem Senses, Vol. 13, pp. 643-653.

30. Teerling, A. The effect of ambient odours on shopping behaviour, Psychological Laboratory, University Utrecht, Holland.

31. Fanger, P. O., Daniewska, M., Knudsen, H. N. and Wargocki, P. 1991. Modification of perceived indoor air qualtiy by addition of fragrances, Institute Report, Laboratory of Heating and Air Conditioning Technical University of Denmark.

32. Teerling, A., 1992, The effect of ambient odours on shopping behaviour, Psychological Laboratory, University Utrecht, Holland.

33. Fanger, P. O., Daniewska, M., Knudsen, H. N. and Wargocki, P. 1991. Modification of perceived indoor air qualtiy by addition of fragrances, Institute Report, Laboratory of Heating and Air Conditioning Technical University of Denmark.

34. Rankin, Krystyna M./McGee, Thomas 1997 The Influence of Product Color on the Perception of Fragrances by Trained and Untrained Assessors Givaudan-Roure Corporation, Teaneck, New Jersey. 